\title{
Neurosurgical management of cerebellar haematoma and infarct
}

\author{
Peter Mathew, Graham Teasdale, Alison Bannan, David Oluoch-Olunya
}

\begin{abstract}
The clinical features, treatment, and outcome were reviewed for $\mathbf{4 8}$ patients with a haematoma and 71 patients with an infarct in the posterior fossa in order to develop a rational plan of management. Clinical features alone were insufficient to make a diagnosis in about half of the series. Patients with a haematoma were referred more quickly to the neurosurgical unit, were more often in coma, and more often had CT evidence of brain stem compression and acute hydrocephalus. Ultimately, $75 \%$ of the patients with a haematoma required an operation. By contrast, most patients with an infarct were managed successfully conservatively. Early surgical management in both cerebellar haemorrhage and infarct (either external ventricular drainage or evacuation of the lesion), associated with early presentation and CT signs of brain stem compression and acute hydrocephalus, led to a good outcome in most patients. Of the patients with cerebellar haematoma initially treated by external drainage, over half subsequently required craniectomy and evacuation of the lesion; but, in some cases, this failed to reverse the deterioration. In patients with a cerebellar infarct, external drainage was more often successful. The guidelines, findings, and recommendations for future management of patients with posterior fossa stroke are discussed.
\end{abstract}

(尹 Neurol Neurosurg Psychiatry 1995;59:287-292)

Keywords: cerebellar haematoma; cerebellar infarct; management

\footnotetext{
Department of Neurosurgery, Institute of

Neurological Sciences, Southern General Hospital, Glasgow G51 4TF, Scotland, UK P Mathew

G Teasdale

A Bannan

D Oluoch-Olunya

Correspondence to: Mr P Mathew.

Received 28 October 1994

and in revised form

30 March 1995

Accepted 19 April 1995
}

formed immediately, as part of a planned strategy, or only after other measures fail to lead to sustained improvement. We have, therefore, carried out a retrospective study of a large series of patients with a "cerebellar stroke" to define their features, treatment, and outcome and hence develop a strategy for future management.

\section{Patients and methods}

The study was performed at the Institute of Neurological Sciences, Glasgow. This regional unit provides neurosurgical, neurological, and neuroradiological services for the west of Scotland, a population of 2.8 million. Patients suspected to have had a stroke are first admitted to the appropriate general hospital and selected patients are then referred to the regional centre for further assessment and treatment.

A high definition CT scanner was installed in the department of neuroradiology in 1986 . We searched the prospectively collected data base in the neuroradiology department and also routine patient records to identify patients with a suspected cerebellar haematoma or infarct, during the six year period February 1986 to December 1991 . We excluded patients with cerebellar infarcts also involving the brain stem, with lesions secondary to aneurysmal subarachnoid haemorrhage, and when the haemorrhage was secondary to trauma, tumour, or other major disease. In each patient the case notes were reviewed to record specific aspects of the clinical history, examination, radiological findings, management, and outcome. Information on outcome was supplemented by contact with general practitioners, patients, and their relatives.

The patients' CT and, when performed, MRI were reviewed by a consultant neuroradiologist who recorded the type of lesion, its site and size, the appearances of basal cisterns and fourth ventricle, and the presence or absence of features of acute hydrocephalus (as defined as a change from the normal crescentric configuration of the temporal horn of the lateral ventricle, to an ovoid appearance and widening of the third ventricle). Neuroradiological evidence of brain stem compression was considered to be present when the basal cisterns were obliterated. Acute hydrocephalus was diagnosed from the appearances of increased diameter of the temporal horns, loss of the triangular shape, widening and ballooning of the third ventricle, 
and enlargement of the lateral ventricles above the size expected from the patient's age.

\section{Results}

Eighty nine patients were identified. Thirty nine had a cerebellar haematoma and 50 had an infarct (table 1).

CLINICAL FEATURES (TABLE 2)

Overall, clinical features did not distinguish clearly between haematoma and infarct and did not reliably identify the precise site of either lesion.

\section{CT FEATURES OF SPACE OCCUPATION AND HYDROCEPHALUS}

Features of brainstem and fourth ventricle compression were found more often than hydrocephalus; in $25 \%$ of patients with features of brainstem and fourth ventricle compression, acute hydrocephalus was absent. With the exception of one patient with cerebellar haemorrhage who had blood in the fourth ventricle, all patients with acute hydrocephalus also had radiological signs of brainstem compression. A haematoma more commonly produced either brainstem compression or hydrocephalus than did an infarct.

\section{Management}

A total of 54 patients were initially managed conservatively. Thirty five patients underwent an operation (external ventricular drainage or craniectomy), 29 as a result of a primary decision and six as a secondary decision after a period of conservative management. In addition, eight patients underwent a craniectomy and evacuation of a mass lesion after initial external ventricular drainage. Thus 14 patients had a management change. A treat-

Table 1 Clinical and radiological characteristics of study sample

\begin{tabular}{lll}
\hline & Haematoma & Infarct \\
\hline Cerebellum & 39 & 50 \\
Mean age (range) & $61(35-80)$ & $57(26-85)$ \\
Presentation <48 hours & $33(85 \%)$ & $22(44 \%)$ \\
& & \\
CT appearances: & $32(82 \%)$ & $26(52 \%)$ \\
Brain stem compression & $24(62 \%)$ & $19(38 \%)$ \\
Acute hydrocephalus & &
\end{tabular}

Table 2 Posterior fossa stroke: conscious level and neurological signs

\begin{tabular}{lll}
\hline & $\begin{array}{l}\text { Cerebellar } \\
\text { haemorrhage }\end{array}$ & Cerebellar infarction \\
\hline $\begin{array}{l}\text { Median GCS } \\
\text { signs (range) }\end{array}$ & $14(3-15)$ & $14(4-15)$ \\
$\begin{array}{l}\text { Cerebellar signs } \\
\text { Brainstem signst }\end{array}$ & $12 / 39$ & $34 / 50$ \\
\hline GCS = Glasgow coma & $19 / 39$ & $12 / 50$ \\
\hline
\end{tabular}

hypotonia; +Horners, long tract signs, cranial nerve palsies. ment limiting decision was made in six patients, all presenting to their initial hospital in coma. These patients all subsequently deteriorated during transfer to the neurosurgical unit.

\section{FEATURES IN PATIENTS IN GROUPS WITH DIFFERENT MANAGEMENT}

Patients in whom the initial management was conservative and in whom this was successful were usually younger, had a higher conscious level (median Glasgow coma score $=14$, range 9-15) and had been referred to the unit 48 hours after onset. This was true for both haematoma and infarct. Of the 14 patients with a haematoma managed successfully conservatively, seven had signs of brainstem compression on the initial CT but only three had hydrocephalus. Of the 34 patients with cerebellar infarction managed successfully conservatively three had acute hydrocephalus. All patients managed successfully with external ventricular drainage (cerebellar haemorrhage and infarction) had acute hydrocephalus and obliteration of the basal cistern. In almost all patients in whom the initial decision was to evacuate the lesion (either haematoma or infarct) both hydrocephalus and signs of radiological brainstem compression were present on initial CT. Operation was more often used initially in the treatment of a patient with haematoma $(54 \%)$, than in those with an infarct $(22 \%)$. All these patients with haematoma $(n=7)$ and one out of two with an infarct, were in coma; more than half had been referred within 48 hours of onset (five of nine).

\section{CHANGES IN MANAGEMENT}

Management was altered more often in patients who had a cerebellar haematoma than in those who had an infarct.

\section{Cerebellar haematoma}

Four out of 18 patients initially treated conservatively subsequently underwent craniotomy and evacuation of the haematoma after deterioration $(n=3)$ or failure to improve $(n=1)$. Half of these patients had brainstem compression and hydrocephalus on the initial CT. In no case was external drainage employed as a secondary measure.

Eleven patients were initially treated by external drainage. Six subsequently had a craniotomy and evacuation of the lesion. In four patients this was in response to clinical deterioration, but in two patients, who were initially in coma, improvement in response to external drainage encouraged an expectation that evacuation of the haematoma would be worthwhile.

\section{Cerebellar infarct}

Of the 36 patients with an infarct initially treated conservatively, only two subsequently underwent operation, in both cases ventriculostomy and external drainage. In each case initial CT had shown acute hydrocephalus and rapid deterioration to coma had occurred 24 hours after transfer. Similarly, of the nine 
patients initially treated with external drainage, evacuation was required in only two.

\section{Outcome}

Outcome was satisfactory in the great majority of cases. Tables 3 and 4 show the interrelation between the type of lesion, the course of management, and outcome.

\section{Cerebellar haematoma}

Thirty six of 39 patients with a haematoma made an independent recovery (moderate disability present in four). Only three patients died; in each case a treatment limiting decision had been made on the basis of the patient's initial clinical and CT features. Otherwise, there was little difference in the quality of recovery irrespective of the type of initial or final management. Of the 10 patients in whom evacuation of the haematoma was carried out as a delayed procedure, nine were considered to have made a good recovery.

\section{Cerebellar infarction}

Forty three of the 50 patients with an infarct made an independent recovery (moderate disability in two). Three patients, in each of whom a treatment limiting decision was made, died. These patients were more than 65 years of age, and were in deep coma with unreacting pupils. Of the 34 patients managed conservatively, all but one made a good recovery. Of the 13 patients who underwent either ventriculostomy or craniotomy, four died and one was disabled. The two patients who were initially managed conservatively, and subsequently underwent external drainage, both died after failing to improve after operation. One patient, treated with external ventricular drainage within 24 hours of onset, rapidly

Table 3 Cerebellar haematoma: management and outcome

\begin{tabular}{lrlll}
\hline & $n$ & Dead & $M D$ & Good \\
\hline Conservative & 14 & - & 2 & 12 \\
EVD & 5 & - & - & 5 \\
Craniectomy & 7 & - & 1 & 6 \\
Management change & 10 & - & 2 & 8 \\
TLD & 3 & 3 & - & - \\
Total & 39 & 3 & 5 & 31 \\
\hline
\end{tabular}

EVD = external ventricular drainage; TLD = treatment limiting decision; $M D=$ moderate disability.

Table 4 Cerebellar infarct: management and outcome

\begin{tabular}{lrllc}
\hline & $n$ & Dead & $M D$ & Good \\
\hline Conservative & 34 & - & 1 & 33 \\
EVD & 7 & 1 & 1 & 5 \\
Craniectomy & 2 & 1 & - & 1 \\
Management change & 4 & 2 & - & - \\
TLD & 3 & 3 & - & 41 \\
Total & 50 & 7 & 2 & 4 \\
\hline
\end{tabular}

For abbreviations see table 3 . deteriorated 18 hours later and died before evacuation could be performed.

Two patients failed to improve after a period of external drainage but made a good recovery after removal of the infarct. Two patients were initially treated by evacuation of the infarct; both were in coma. In one this had developed acutely after the onset of infarction and despite evacuation at 12 hours the patient died. In the second patient coma developed after delay of more than 24 hours and the patient recovered after evacuation.

\section{Discussion}

Most patients with a posterior fossa stroke make a good recovery. This may follow management which is ultimately conservative, or drainage to relieve hydrocephalus, or evacuation of the lesion to relieve both local space occupying effects and hydrocephalus. In this study, initial management strategy had to be changed in a substantial proportion of patients. Most such patients recovered so that an approach to management based on modification of treatment in the light of a patient's progress could be seen as appropriate. In a small proportion of our series, however, poor outcome followed the failure of an initially overconservative approach, then deterioration that could not be reversed by operative intervention. We think that a strategy based on more clear guidelines for early surgical treatment may reduce such potentially avoidable mortality and morbidity without exposing other patients to the risk of operative complications from unnecessary intervention.

Outcome in present and previous series

The favourable outcome in this series is in accord with many previous reports. ${ }^{2461011-15}$ This is particularly seen in patients in whom conservative treatment was successful, reflecting the less severe state of such cases.

In many previous reports of cerebellar haematoma, most patients were in coma and outcome has been more variable. ${ }^{371416}$ Mortality for patients in a coma before operation has been reported to range between 35\% and $100 \% .{ }^{3816-18}$ In this series, patients with a haematoma who presented in a coma or deteriorated into a coma and underwent craniectomy and excision had a good recovery. Outcome after external drainage was good only if a patient did not deteriorate and require an operation.

Patients with a cerebellar infarct treated with external drainage often had a satisfactory course but in others drainage was followed by deterioration that could not be reversed by subsequent evacuation.

\section{Features of differently managed groups in the} present series

With the exception of patients who were conscious with no acute hydrocephalus on initial CT (particularly when this was their state 48 hours after onset), clinical features and CT evidence of brainstem compression, size, and site of the lesion, could not identify patients in 


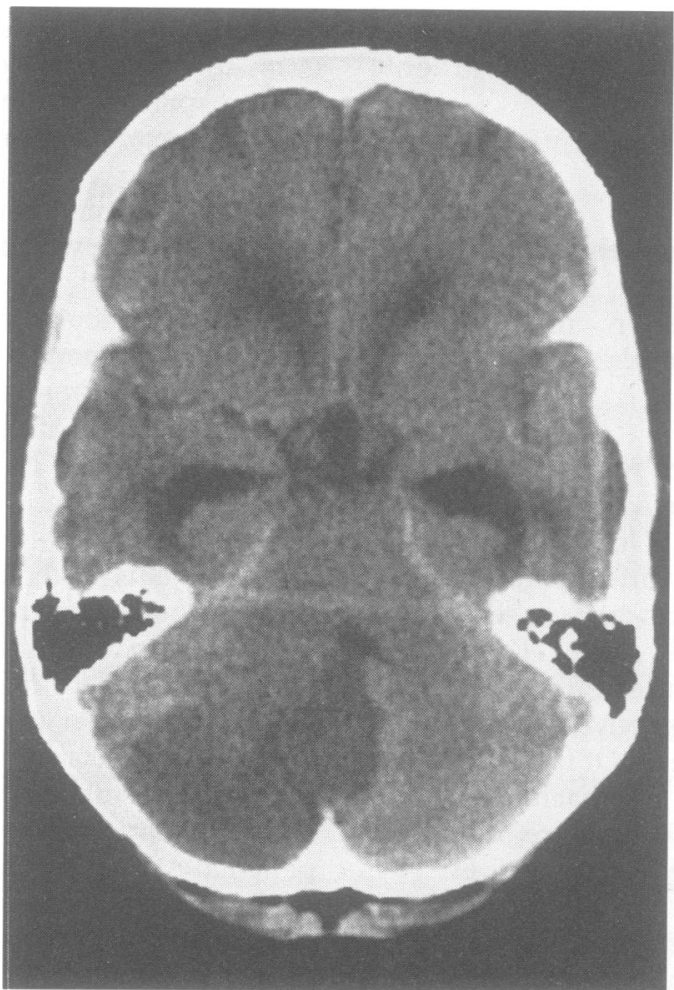

Figure 1 Drowsy, disoriented patient: CT shows left PICA territory infarct with obliteration of the basal cisterns and fourth ventricle, and associated acute hydrocephalus. Sustained, rapid improvement in level of consciousness after external ventricular drainage.

whom conservative treatment was consistently successful. This is by contrast with previous reports. ${ }^{12}{ }^{19-29}$

Patients who presented within 48 hours, with CT evidence of hydrocephalus irrespective of conscious level were usually treated initially by drain or evacuation (figs 1 and 2). Although most patients in whom external drainage was successful had been referred within 48 hours and were conscious, it was otherwise not possible to predict from clinical or CT features the patients who subsequently required craniectomy because of deterioration.

\section{Potentially avoidable mortality and morbidity} Management that is either inadequate or delayed, or unnecessarily interventional, may result in an outcome worse than that otherwise expected. In this series, operative intervention was employed as the initial management in the minority of patients and in neither these nor those in which it was employed secondarily, was a poor outcome caused by a complication of surgery. Although there is concern about "upward herniation" in patients with posterior fossa lesions treated by external drainage ${ }^{183031}$ this is rare. The CT features believed to indicate this danger were not found in this series. ${ }^{32}$ Another concern is that craniectomy and evacuation of the lesion may not adequately relieve hydrocephalus, at least until acute swelling has resolved. ${ }^{12}$ In no case in this series was external ventricular drainage required after initial treatment by

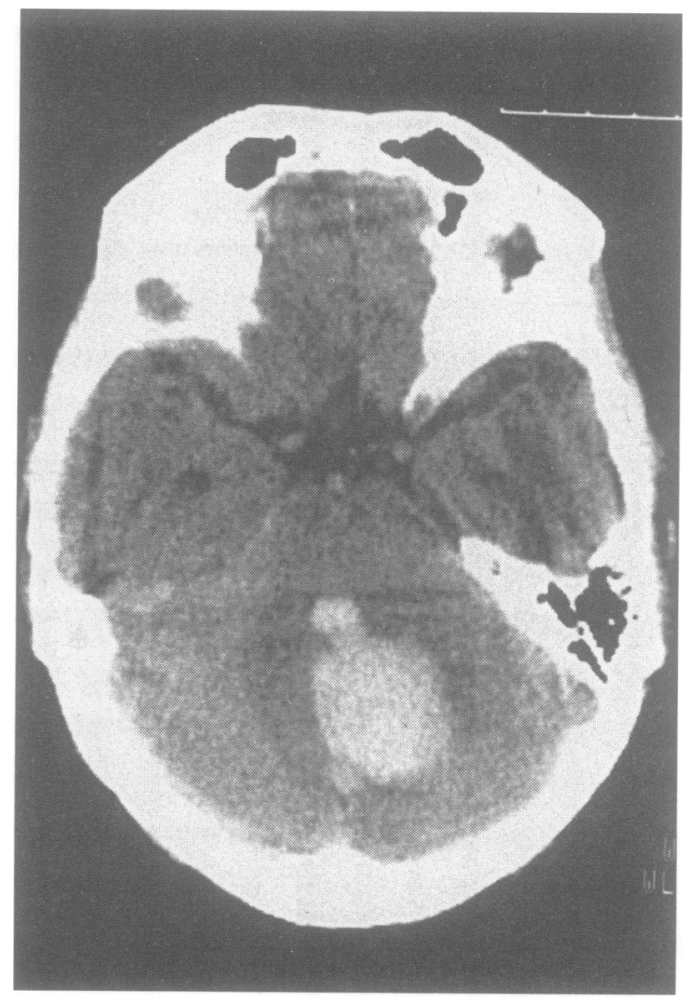

Figure 2 Patient presenting in coma within 48 hours: CT shows large right cerebellar haemorrhage with extension into fourth ventricle. Successful outcome after suboccipital decompression of haematoma. No drain.

craniectomy and none of these patients required a delayed shunt.

Inadequate treatment of either local occupation of posterior fossa space or hydrocephalus caused by a mass lesion in the posterior fossa may worsen outcome. Each of these events were found in this series, in two patients initially managed conservatively and in a third patient initially treated with external drainage. These patients died.

In patients with a cerebellar haematoma or infarct, the initial management approach was usually successful. For those who required a change in management, the strategy was usually successful in those with a cerebellar haematoma but in only half of those with a cerebellar infarct. Additional damage in patients with an infarct may have been due to brainstem compression, hydrocephalus, or extension of the infarct. ${ }^{4}$ The limitation of CT leads to an underestimation of the role of infarction at first presentation and in patients who deteriorate secondarily. ${ }^{9}$

\section{Recommendations (figs 3 and 4)}

In the patient with either a haematoma or an infarct in the cerebellum the prospects for a satisfactory outcome can be improved by a strategy that balances the benefits of a conservative approach with the need for timely operation to avoid deterioration due to inadequate or delayed intervention. The two main criteria on which the strategy is based are clinical (conscious level) and CT (hydrocephalus).

A patient with either an infarct or a 


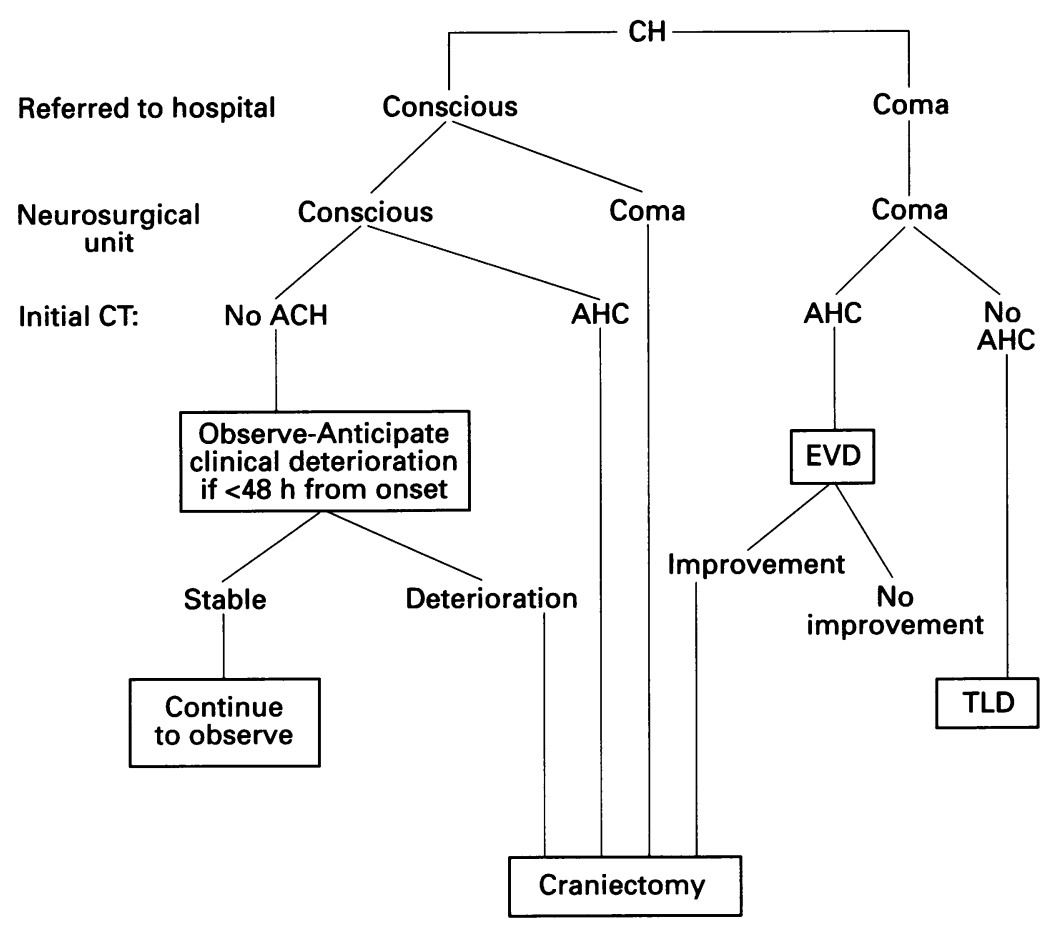

Figure 3 Recommendations for neurosurgical management of cerebellar haematoma; $C H=$ cerebellar haematoma; $C I=$ cerebellar infarct; $A H C=$ acute hydrocephalus; EVD = external ventricular drainage; TLD = treatment limiting decisions.

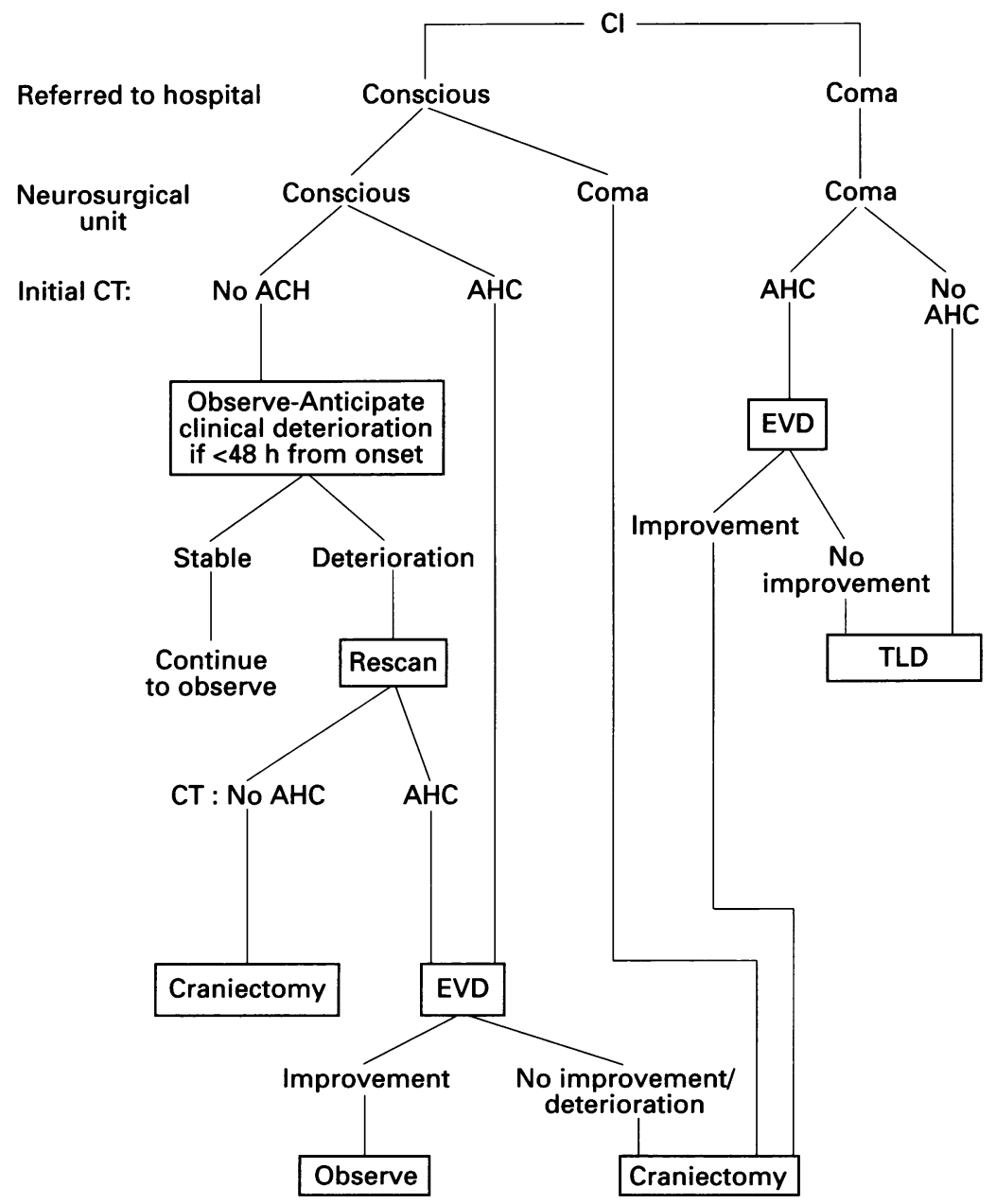

Figure 4 Recommendations for neurosurgical management of cerebellar infarct (CI). For abbreviations see fig 3. haematoma who is conscious, and whose initial CT does not show hydrocephalus, can be managed by careful clinical observation. This approach is almost always successful when 48 hours has elapsed since the onset of the stroke, but until this time, there must be awareness of the possibility of acute deterioration. If CT shows acute hydrocephalus, surgical intervention should be advised.

The patient with an infarct and hydrocephalus and preserved consciousness can reasonably be initially treated by external ventricular drainage. Failure to improve, or deterioration, should be the signal for urgent decompression. In a patient with a cerebellar haematoma and hydrocephalus, this is invariably associated with local evidence of brainstem compression and the preferred approach is evacuation of the haematoma.

For a patient in a coma, the appropriate approach can be guided by the clinical changes between onset and referral and CT. If coma has developed secondarily, the patient should be treated by urgent evacuation of the infarct or haematoma. If the patient has been in a coma from the onset, or if the patient is in a deep coma after secondary deterioration and has hydrocephalus we advise external drainage followed by observation of the patient's response. Should the patient improve the lesion should be evacuated; if the patient fails to improve, a treatment limiting decision becomes appropriate. If coma has been present from onset, and further deterioration has occurred after transfer, in the absence of hydrocephalus a treatment limiting decision may be made.

1 Freeman JW, Kennedy RM, Pettys S. Prognosis of nonoperated cerebellar haemorrhage. Ann Neurol 1978;4: 389-90.

2 Heinemann TD, Satya-Murti S. Benign cerebellar haemorrhage. Ann Neurol 1978;3:366-8.

3 Kahn M, Polyzoldis KS, Adegbite ADO, McQueen JD. Massive cerebellar infarction: "conservative" management. Stroke 1983;14:745-51.

4 Laur A, Busse O, Calatayud V, Klug N. Cerebellar infarcts in the area of supply of the PICA and their surgical treatin the area of supply of the PICA and their surgica

5 Lui T-N, Fairholm DJ, Shu T-F, Chang CN, Lee ST, Chen HR. Surgical treatment of spontaneous cerebellar Chen HR. Surgical treatment of spontaneous
haemorrhage. Surg Neurol 1985;23:555-8.

6 Ott KH, Kage CB, Ojemann RG, Mohr JP. Cerebellar haemorrhage: diagnosis and treatment. Arch Neurol 1974;31:160-7.

7 Steiner I, Gomori JM, Melamed E. The prognostic value of the CT scan in conservatively treated patients with intracerebral haematoma. Stroke 1984;15:279-82.

8 Brennan RW, Bergland RM. Acute cerebellar haemorrhage: analysis of clinical findings and outcome in 12 cases. Neurology 1977;27:527-32.

9 McKissock E, Richardson A, Walsh J. Spontaneous cerebellar haemorrhage. Brain 1960;83:1-9.

10 Tsai FY, Teal JS, Heishima GB, et al. Computed tomography in acute posterior fossa infarcts. AfNR Am $\mathfrak{f}$ phy in acute posterior

11 Chin D, Carney P. Acute cerebellar haemorrhage with brainstem compression in contrast with benign cerebellar haemorrhage. Surg Neurol 1983;19:406-9.

12 Fisher CM, Picard EK, Polak A. Acute hypertensive cerebellar haemorrhage: diagnosis and surgical treatment. f Nerv Ment Dis 1965;140:38-57.

13 Heros RC. Cerebellar haemorrhage and infarction. Stroke 1982;13:166-9.

14 MacDonnell RAL, Kalanis RM, Donnan GA. Cerebellar infarction: natural history, prognosis and pathology. Stroke 1987;18:849-55.

15 Shenkin HA, Zavala M. Cerebellar strokes: mortality, surgical indications and results of ventricular drainage. Lancet 1982;ii:429-31.

16 Pozzati E, Grossi C, Padovani R. Benign traumatic intracerebellar haematoma. f Neurosurg 1982;56:691-4. 
17 Greenberg J, Skubick D, Shenkin H. Acute hydrocephalus in cerebellar infarction and haemorrhage. Neurology 1979;29:409-13.

18 Salazar J, Vaquero J, Martinez P. Clinical and CT scan assessment of benign versus fatal spontaneous cerebellar assessment of benign versus fatal spontane 1986;79:80-6.

19 Cioffi FA, Bernini FP, Punzo A, D'Avanzo R. Surgical management of acute cerebellar infarction. Acta management of acute cerebell

20 Little JR, Tubman DE, Ethier R. Cerebellar haemorrhage in adults: diagnosis by computerised tomography. f Neurosurg 1978;48:575-9.

21 Richardson AE. Spontaneous cerebellar haemorrhage. In: Vinken PJ, Bruyn GU, eds. Handbook of clinical neurology. New York: Elsevier, 1972:54-67.

22 Seelig JM, Selhorst JB, Young HF, Lipper $M$ Ventriculoscopy for hydrocephalus in cerebellar haemorrhage. Neurology 1981;31:1537-40.

23 Sypert GW, Alvord EC. Cerebellar infarction. Arch Neurol 1975;32:357-63.

24 Taneda M, Hayakawa T, Mogami H. Primary cerebellar haemorrhage. Quadrigeminal cistern obliteration or CT haemorrhage. Quadrigeminal cistern obliteration or C1: scans as
25 Taneda $M$, Ozaki K, Wakayama A, Yagi K, Kaneda JH, Irino $\mathrm{T}$. Cerebellar infarction with obstructive hydrocephalus. $\mathcal{F}$ Neurosurg 1982;57:83-91.

26 Turner DA, Howe JF. Cerebellar haemorrhage as evaluated by computerised tomography. West H Med 1982; 136:198-202.

27 Van der Hoop RG, Vermeulen M, Van Gijn J. Cerebellar haemorrhage: diagnosis and treatment. Surg Neurol 1988;29:6-10.

28 Weisberg LA. Acute cerebellar haemorrhage and CT evidence of tight posterior fossa. Neurology 1986;36:858-60.

29 Wieger A, Vonodalps D, Stendel WI, Dusterbehn G. Nonieger $A$, Vonodalps $D$, Stendel traumatic intracerebellar haematomas: prognostic value of volumetric evaluation

30 Dinsdale HD. Spontaneous haemorrhage in the posterior fossa: a study of primary cerebellar and pontine haemorrhage with observations on their pathogenesis. Arch Neurol 1964;10:200-17.

31 Melamed N, Satya-Murti S. Cerebellar haemorrhage: a review and reappraisal of benign cases. Arch Neurol $1984 ; 41: 425-8$

32 Cuneo RA, Caronna TJ, Winestock PP. Upward transtentorial herniation. Arch Neurol 1979;36:618-23. 